\title{
Chronic inflammatory demyelinating polyneuropathy and Type 1 lepra reaction: a rare association
}

\author{
Archana Suresh $^{\mathrm{a}}$, Abhay Mani Martin ${ }^{\mathrm{b}}$, Sarita Sasidharanpillai $^{\mathrm{c}}$, \\ Joe James ${ }^{\mathrm{d}} \&$ James Jose ${ }^{\mathrm{d}}$ \\ ${ }^{a}$ Department of Dermatology, Govt. Medical College, Kannur, Kerala, India \\ ${ }^{\mathrm{b}}$ Department of Dermatology, Baby Memorial Hospital, Kozhikode, Kerala, \\ India \\ ${ }^{\mathrm{c}}$ Department of Dermatology, Govt. Medical College, Kozhikode, Kerala, \\ India \\ ${ }^{\mathrm{d}}$ Department of Neurology, Govt. Medical College, Kozhikode, Kerala, India
}

Submitted 23 April 2021; Accepted 2 August 2021

\begin{abstract}
Summary Lepra reactions are important causes of the disability and deformity associated with leprosy. Normal body tissues suffer during these periods of hypersensitivity response mounted by the body against the antigens of Mycobacterium leprae. Chronic demyelinating polyneuropathy manifesting several years after reversal reaction is reported in the literature. It is attributed to the autoimmune reaction precipitated by the exposure of neural antigens (following the injury caused by the Type 1 lepra reaction) to the body's immune system. Here we report a patient who presented with chronic inflammatory demyelinating polyneuropathy during a Type 1 lepra reaction.
\end{abstract}

Keywords: Chronic inflammatory demyelinating polyneuropathy, Type 1 lepra reaction, leprosy

\section{Introduction and case report}

Lepra reactions play a major role in the disability associated with leprosy. ${ }^{1}$ Here we report the case of a 71 year old man who manifested chronic inflammatory demyelinating polyneuropathy (CIDP) along with Type 1 lepra reaction (T1R). Written, informed consent was obtained from the patient.

The patient presented with erythematous, oedematous plaques (Figure 1) distributed over the trunk and limbs, of two weeks duration. The skin lesions showed impaired perception of touch, pain and temperature. The right ulnar nerve was enlarged and tender with sudden onset of ulnar clawing of one week duration. He also showed ulnar sensory nerve function

Correspondence to: Sarita Sasidharanpillai (e-mail: saritasclt@gmail.com)

The work has been done in the Departments of Dermatology and Neurology, Govt. Medical College, Kozhikode, Kerala, India. 


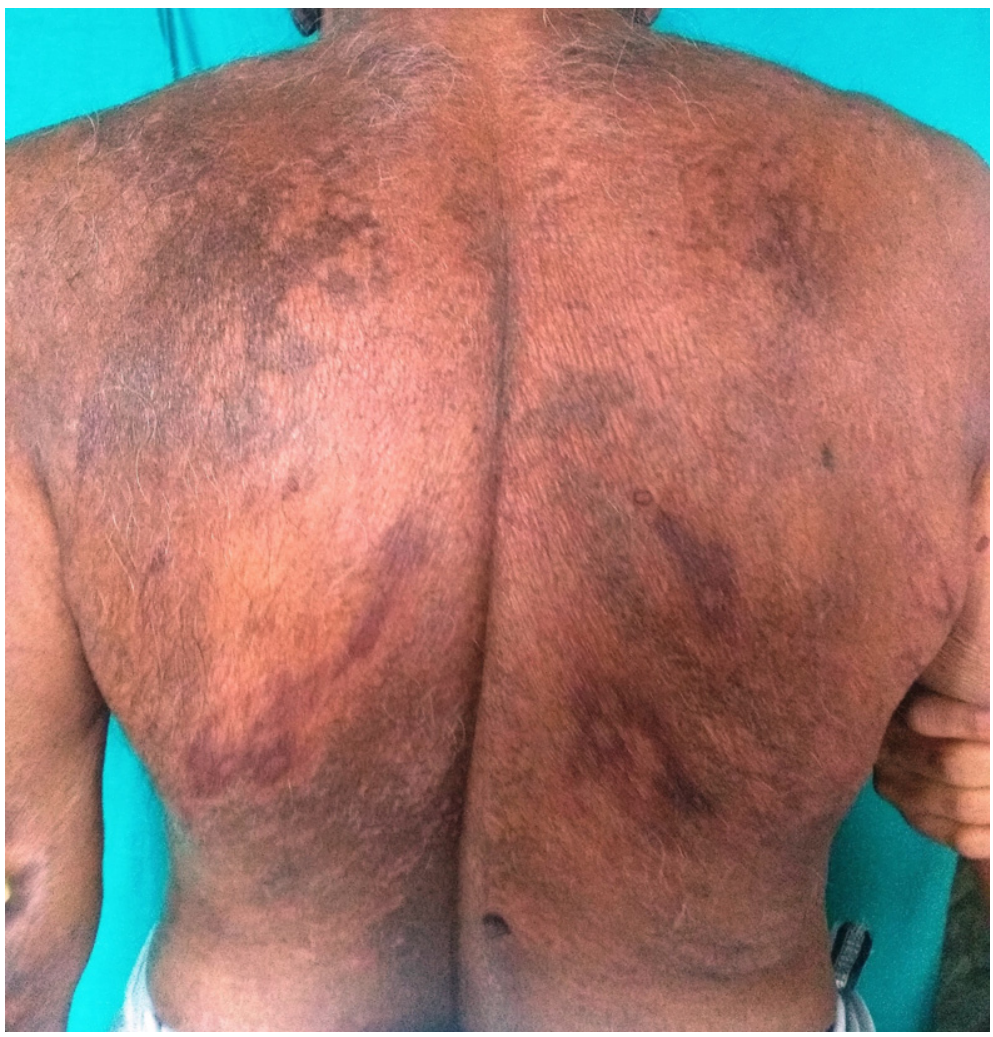

Figure 1. Erythematous plaques in borderline tuberculoid leprosy with Type 1 lepra reaction.

impairment. No other abnormality was detected on examination of the nervous system. Slit smears from the lesional and normal skin, and the ear lobe were negative for acid fast bacilli. Histopathology (Figure 2) of lesional skin confirmed the diagnosis of borderline tuberculoid leprosy with Type 1 lepra reaction. He received rifampicin $600 \mathrm{mg}$ once a month, clofazimine $50 \mathrm{mg}$ once a day and $300 \mathrm{mg}$ once a month and dapsone $100 \mathrm{mg}$ once a day for leprosy. Prednisolone $30 \mathrm{mg} /$ day was initiated concurrently for the ulnar neuritis associated with Type 1 reaction. Within three weeks of treatment with dapsone, the patient developed a haemolytic anaemia. Hence dapsone was substituted with ofloxacin $400 \mathrm{mg} /$ day. After one month, prednisolone was tapered to $20 \mathrm{mg}$, when he showed improvement of the ulnar neuritis. He did not have any other comorbidities and denied history of intake of any drugs other than those prescribed. The patient opted to attend a nearby primary health centre for further treatment and follow up.

Fourteen weeks after the diagnosis of leprosy and initiation of multidrug therapy, the patient presented with a nasal twang to the voice, nasal regurgitation of fluids, reduced sensory perception on the legs and weakness of limbs, which increased progressively over a period of nine weeks.

A detailed neurological examination revealed normal cognitive functions and normal cranial nerves except for absent gag reflexes bilaterally. All modalities of sensation (touch, pain, temperature, vibration and joint position sense) were reduced up to the knees in the lower 


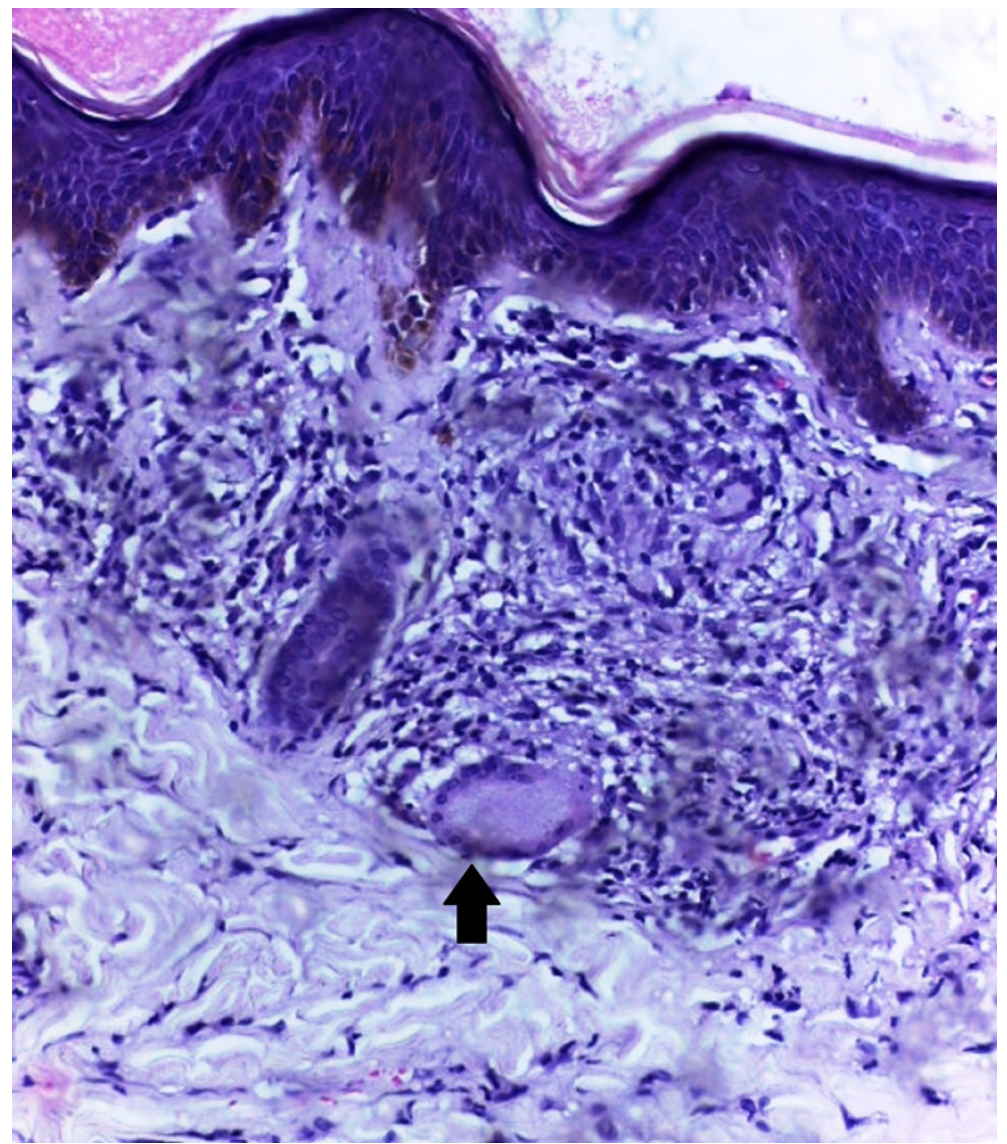

Figure 2. Skin biopsy showing epithelioid granuloma, Langhan's giant cells (black arrow), intragranuloma oedema and dermal oedema, suggestive of borderline tuberculoid leprosy in Type 1 lepra reaction (H\&E, 200×).

limbs and up to the elbows in the upper limbs. Power was grade 2 proximally and grade 4 distally in both upper and lower limbs on the MRC 0-5 scale for voluntary muscle testing. All deep tendon reflexes were absent and plantar reflexes were mute bilaterally. He was unable to stand without support. The patient showed no signs of cerebellar involvement.

Complete hemogram, urine microscopy, serum electrolytes, glycaemic status, renal and liver function tests and serum electrophoresis were within normal limits. Serological tests for syphilis, human immunodeficiency virus and collagen vascular diseases were negative.

Nerve conduction studies showed reduced conduction velocity with prolonged distal motor latencies and F-wave latencies in the median, ulnar, peroneal and tibial nerves bilaterally, consistent with demyelination (Table 1). Cerebrospinal fluid analysis showed albuminocytological dissociation (protein $106 \mathrm{mg} \%$, leukocytes 3 cells $/ \mathrm{mm}^{3}$ ). Magnetic resonance imaging of the brain was normal.

With a diagnosis of chronic inflammatory demyelinating polyneuropathy, the patient received intravenous immunoglobulin $\mathrm{G}(\mathrm{I} / \mathrm{V} \mathrm{IgG})$ at $20 \mathrm{gm} /$ day for 5 days repeated after 28 days. $^{2}$ MDT and oral corticosteroids were continued. Owing to a lack of response after two pulses, he was referred to a higher centre, where he received a cyclophosphamide pulse 
Table 1. Nerve conduction study of the patient, indicating demyelination

\begin{tabular}{lccccc}
\hline \multicolumn{2}{c}{ Motor nerves } & $\begin{array}{c}\text { Distal latency in ms } \\
\text { Patient (normal) }\end{array}$ & $\begin{array}{c}\text { Amplitude in mV } \\
\text { Distal/proximal } \\
\text { patient (normal) }\end{array}$ & $\begin{array}{c}\text { Conduction velocity in m/s } \\
\text { Patient (normal) }\end{array}$ & $\begin{array}{c}\text { F-wave in ms } \\
\text { (upper limit } \\
\text { of normal) }\end{array}$ \\
\hline \multirow{2}{*}{ Median } & Right & $5.67(<4.2)$ & $3.2 / 3.0(>4.5)$ & $34(>49)$ & $39.3(28.5)$ \\
& Left & $6.13(<4.2)$ & $2.2 / 1.9(>4.5)$ & $36(>49)$ & $41.2(28.5)$ \\
Ulnar & Right & $5.55(<4.0)$ & $4.1 / 4.0(>5.0)$ & $29(>47)$ & $44.3(28.9)$ \\
Common & Left & $5.20(<4.0)$ & $3.1 / 2.8(>5.0)$ & $33(>47)$ & $42.5(28.9)$ \\
peroneal & Right & $13.6(<6.5)$ & $0.2 / \mathrm{NR}(>2.5)$ & $16(>37)$ & $\mathrm{NR}(47 \mathrm{~ms})$ \\
& Left & $12.2(<6.5)$ & $0.8 / 0.2(>2.5)$ & $21(>37)$ & $\mathrm{NR}(47 \mathrm{~ms})$ \\
Tibial & Right & $11(<7)$ & $1.1 / 0.2(>2.5)$ & $18(>37)$ & $\mathrm{NR}(55 \mathrm{~ms})$ \\
& Left & $16(<7)$ & $0.4 / \mathrm{NR}(>2.5)$ & & $\mathrm{NR}(55 \mathrm{~ms})$ \\
\hline
\end{tabular}

NR: not recordable.

(500 mg intravenously for three days) followed by a methyl prednisolone pulse ( $1 \mathrm{~g}$ daily for five days). ${ }^{3}$ He received five more pulses of cyclophosphamide at 28-day intervals, followed by azathioprine $50 \mathrm{mg}$ daily for six months, during which he attained a gradual resolution of symptoms. The patient had a complete recovery of his bulbar palsy and marked improvement in the weakness of limbs. He successfully completed one year of MDT and has remained asymptomatic during the follow up period of eighteen months. Prednisolone prescribed for T1R was tapered and stopped over a four month period.

\section{Discussion}

Despite its declared 'elimination' status, leprosy is not an uncommon disease in India, particularly in a tertiary care setting. ${ }^{4}$ Type 1 and Type 2 lepra reactions are important causes of leprosy-associated disability, in which the normal tissues and organs are affected by type IV and type III hypersensitivity responses respectively, mounted by the body against the antigens of Mycobacterium leprae. ${ }^{5,6}$

CIDP is a less common immune-mediated neuropathy that shows peripheral nerve demyelination and a relapsing-remitting course. ${ }^{7}$ A slowly progressive onset of symmetrical, sensorimotor deficit in the limbs over two months, areflexia, the nerve conduction study findings and the albumino-cytological dissociation in the cerebrospinal fluid analysis were diagnostic of CIDP in our case. ${ }^{2}$ Cranial nerve palsy, though less frequent, is reported in CIDP with facial and bulbar palsy being the most common. ${ }^{8}$ Cranial nerve palsy (when present in CIDP), is often bilaterally symmetrical and is associated with more severe limb muscle weakness, as observed in our patient. ${ }^{8}$ The exact pathogenesis of CIDP remains unclear, but it is considered to be an autoimmune disease mediated by autoreactive $\mathrm{T}$ and $\mathrm{B}$ cells. ${ }^{9} \mathrm{CIDP}$ is reported in association with other autoimmune diseases like diabetes mellitus and Sjogren's syndrome, neoplastic conditions including melanoma and lymphoma, and infections due to human immuno-deficiency virus and hepatitis $\mathrm{C}$ virus. ${ }^{9}$

While there are occasional reports of Guillain Barre syndrome as a manifestation of T1R/T2R, ${ }^{10,11}$ CIDP in lepra reaction is rare. Andrade et al. reported a patient who developed CIDP 12 years after the completion of treatment for mid borderline leprosy. ${ }^{9}$ At the time of CIDP, he also had T1R. He received methylprednisolone pulse therapy. His skin lesions (which were diagnosed as due to TIR) subsided in two months while the pulse therapy was continued monthly for six months. He also attained relief of his neurological symptoms. The authors 
proposed that the neural antigens exposed by the injury caused by T1R could have precipitated an autoimmune reaction that led to CIDP. ${ }^{9}$

Kim et al. reported a patient with leprosy neuropathy who was misdiagnosed as CIDP based on the sensory motor polyneuropathy on nerve conduction study and the scattered mononuclear inflammatory cell infiltration with mild fibrosis noted in a sural nerve biopsy. The diagnosis of leprosy was made when the histopathology specimen showed acid fast bacilli on Ziehl-Neelsen staining. The authors highlighted the preservation of deep tendon reflexes in their case as the differentiating clue from CIDP. ${ }^{12}$ The deep tendon reflexes were absent in our patient.

We did not come across any previous report of chronic inflammatory demyelinating polyneuropathy that coexisted with Type 1 lepra reaction. We report this case to highlight the rare association of chronic inflammatory demyelinating polyneuropathy and Type 1 lepra reaction.

\section{Declaration}

The authors declare that this article has not been published in its present form in any other scientific journal.

\section{Copyright}

The authors agree that the article is offered to Leprosy Review alone, that it will be subject to editorial revision and that its copyright becomes the property of Leprosy Review alone.

\section{Competing interest}

All authors declare that the answers to the questions on your competing interest form are all no and therefore have nothing to declare.

\section{References}

1 Harboe M. Overview of host parasite relations. In: Hastings RC, Opromolla DVA (eds), Leprosy. 2nd edn, Edinburgh: Churchill Livingstone, 1994; pp. 87-112.

2 Van den Bergh PYK, Hadden RDM, Bouche P, Cornblath DR, Hahn A, Illa I et al. European Federation of Neurological Societies/Peripheral Nerve Society Guideline on management of chronic inflammatory demyelinating polyradiculoneuropathy: Report of a joint task force of the European Federation of Neurological Societies and the Peripheral Nerve Society-First Revision. Eur J Neurol, 2010; 17: 356-363.

3 Yoon MS, Chan A, Gold R. Standard and escalating treatment of chronic inflammatory demyelinating polyradiculoneuropathy. Ther Adv Neurol Disord, 2011; 4: 193-200.

4 Premachandran M, George N, Binitha T, Nandakumar V, Jishna P, Sasidharanpillai S et al. Are children safe from complications of leprosy? A study from North Kerala. J Skin Sex Transm Dis, 2020; 2: 31-34.

5 Ridley DS. Reactions. In: Ridley DS (ed.), Pathogenesis of Leprosy and Related Diseases. vol. 15, UK: Butterworth and Co-publishers Ltd, 1988; pp. 118-134.

6 Nadeem A, Jishna P, Sasidharanpillai S, Bindu V, Vidya AS, Rahima S. Type 2 lepra reaction presenting as nasal septal perforation: A case report. J Skin Sex Transm Dis, 2020; 2: 137-139.

7 Dalakas MC. Advances in the diagnosis, pathogenesis and treatment of CIDP. Nat Rev Neurol, 2011; 7: 507-517.

8 Shibuya K, Tsuneyama A, Misawa S, Suichi T, Suzuki Y, Kojima Y et al. Cranial nerve involvement in typical and atypical chronic inflammatory demyelinating polyneuropathies. Eur J Neurol, 2020; 27: 2658-2661.

9 Andrade LR, Jardim MR, Pitta IJR, Giesel LM, Silveira RC, Vital RT et al. Chronic inflammatory demyelinating polyneuropathy in a patient with a leprosy reversal reaction: A case report. Arch Clin Infect Dis, 2017; 1: 1-3.

10 Dash D, Saluja A, Singh RK, Bhatia R, Tripathi M. Guillain-Barre syndrome: A rare presentation of borderline tuberculoid leprosy with type 1 lepra reaction. J Neurosci Rural Pract, 2018; 9: 423-425.

11 Grover C, Kubba S, Nanda S, Kumar V, Reddy BS. Leprosy with Guillain Barre Syndrome: A new neurologic manifestation? J Dermatol, 2004; 31: 119-123.

12 Kim SH, Shin HY, Kim SM, Kwon KH, Minn YK. Leprotic neuropathy misdiagnosed as chronic inflammatory demyelinating polyneuropathy. Lepr Rev, 2012; 83: 93-97. 